\title{
Current Trends in Pediatric Robotic Surgery
}

\author{
Isabella Garcia \\ Ismael A. Salas de Armas \\ Ashwin Pimpalwar* \\ Division of Pediatric Surgery \\ Michael E. Debakey Department of Surgery \\ Baylor College of Medicine and \\ Texas Children's Hospital, \\ Houston, Texas, USA
}

Correspondence to:

\author{
Ashwin Pimpalwar \\ MD, FRCS(Ped Surgery), Mch (Ped Surgery), \\ EBPS(Ped Surg), MS, DNB \\ Assistant Professor \\ Division of Pediatric Surgery \\ Michael E DeBakey Department of Surgery \\ Baylor College of Medicine and \\ Texas Children's Hospital \\ 6607 Fanin Street \\ CCC 12th Floor \\ Houston, TX 77030
}

\section{INTRODUCTION}

Who would have ever imagined a few decades ago, when the first laparoscopic surgeries were considered dangerous and risky, that today's surgeons routinely perform laparoscopy and other minimally invasive surgical (MIS) procedures on a daily basis to ease the pain and suffering of their patients with increasingly superior surgical and cosmetic outcomes? Laparoscopy dates back nearly a century ago when the first procedures were performed in dogs and subsequently in human patients. With the development of anesthesia and aseptic techniques, surgery reached a new paradigm. Laparoscopic surgery was officially introduced by Kelling in 1910 when he was able to explore an insufflated abdomen with a cystoscope $^{1}$. The first use of laparoscopy by a general surgeon was in 1985 when Muhe described a laparascopic cholecystectomy which in short time became the standard of care for cholelithiasis and cholecystitis ${ }^{2}$. However, the procedures always tended to be limited not only by the operating surgeons' skill set but also by technological developments. It was not until the early 1980s that Dr. Kurt Semm brought laparoscopy to the forefront when he performed and published the first laparoscopic appendectomy ${ }^{3}$. At that time, only three decades ago, Dr. Semm stirred up great controversy with his procedure and he was even called unethical in trying to attempt such unnecessary and dangerous trials. His opponents criticized his attempt at innovation. However, the time was right for change and laparoscopy took off like a rocket soon after with more and more companies investing into the development of laparoscopic instrumentation and medical institutions training surgical residents in laparoscopic procedures. The great advantages were clear. Laparoscopy, due to decreased incisions and manipulation, had the potential to revolutionize surgery, translating to decreased postoperative pain and hospital stay for the patient ${ }^{4}$. In the 1990 s the introduction of MIS led to revolutionary changes in the field of operative medicine. However, as laparoscopy became used by an increasingly growing number of surgeons for a vast variety of procedures, the laparoscopic and thoracoscopic techniques were shown to have technical limitations and certain disadvantages, especially when sophisticated procedures were carried out ${ }^{5}$. Most of the technically advanced operations were and still are difficult to perform in a minimally invasive setting and involve a steep learning curve for the entire surgical team. Other pitfalls of traditional laparoscopy include unstable video camera platform, limited motion of straight laparoscopic instruments, $2 \mathrm{~d}$ imaging and poor ergonomics ${ }^{6-7}$.

Despite these disadvantages, the positive aspects greatly outweigh the negative ones and nowadays, laparoscopy is the standard of care for appendectomies, cholecystectomies, and a wide variety of other general surgery and surgical subspecialty procedures (eg fundoplications, cholecystectomy, gastric banding, colectomy, esophagectomy, sub/total gastrectomy, gastrojejunostomy, thymectomy, thoracic sympathectomy, lobectomy, mediastinal parathyroidectomy, left pancreatic resection and many more $)^{6,8}$.

Despite great promises, pediatric surgeons were initially hesitant to accept laparoscopic surgery for common use in small children due to uncertainty about instruments and machinery because they were originally developed for use in adult patients ${ }^{9}$. 
The often quoted benefits of smaller scars, less pain and shorter hospital stay had initially not been shown to be true in pediatric patients. However, in the mid 1990s, surgeons began publishing laparoscopic pediatric cases, showing laparoscopy to be a potential alternative for children ${ }^{10}$. As in adults, pediatric MIS began with laparoscopic cholecystectomies and appendectomies ${ }^{2}$.

With the advent of laparoscopy and the attempt at perfection of the laparoscopic technique and instrumentation both in adult and pediatric medicine, came the desire to improve surgery even further and try to improve the limitations of the current technique. If it was possible to perform laparoscopy with few small incisions, why not attempt to decrease the number of incisions even further, or perhaps eliminate them all together? These thought processes led to the innovative surgical techniques known as Single Incision Laparoscopic Surgery (SILS) and Natural Orifice Transluminal Endoscopic Surgery (NOTES) in which only one incision, generally in the umbilicus, is made in the former and no outward incision whatsoever in the latter ${ }^{11-16}$. These procedures culminate the current efforts of minimally invasive surgery and their development is still in progress. Only the future will tell how far these procedures will be developed and popularized. Many experts agree that the prospect of minimally invasive adult and pediatric surgery involves SILS, NOTES, and robotic surgery ${ }^{2,17-18}$. Telerobotic surgery has emerged as a promising technical innovation and it seems to offer potential solutions to the limitations of traditional laparoscopy ${ }^{19-22}$.

Technological developments have always been at the forefront of human society and medicine is no different in this aspect. Even before Dr. Semm performed the first laparoscopic appendectomy in Germany in 1981, robotics made an appearance in 1973 with the first industrial robot with several electromechanically driven axes and even before then in more primitive versions. Medicine soon after took notice and the first surgical robot was used in 1983 in Vancouver, Canada by Dr. James McEwen and Geof Auchinlek, in collaboration with orthopedic surgeon, Dr. Brian Day. Another decade passed until robotic surgery was ready to be performed by others. In the late 1990s, two surgical robots, Zeus and Da Vinci, were developed and used for several procedures, which included fallopian tube reconnection and heart bypass. The Da Vinci system was primarily developed for cardiac surgery and was the first robotic system to be approved by the FDA for intraabdominal surgery in the US (July 2000) ${ }^{23}$. More than 750 systems are currently in use in several institutions worldwide $^{6}$. Robotic surgery connects the instruments to the surgeon electronically, making it possible to separate the performance of the operation from the location of the patient, thus enabling telesurgery ${ }^{24-29}$.
However, robotics has mostly been explored in adult and adolescent surgery and less commonly in the pediatric patient population, because this population constitutes additional surgical complicating factors due to limited workspace and different physiology from their adult counterparts ${ }^{30-34}$. Additionally, surgical robots have been developed for use in adults and for some time had not been adapted for use in children. These are some of the reasons robotics has been slow to take off in pediatric surgery ${ }^{35}$.

Yet, with the advent of robotics, despite its of right now limited application in pediatrics, surgeons began dreaming about fixing fetal diaphragmatic hernias or myelomeningoceles in utero because the robot's computer can scale down a surgeon's hand movements into micromotions inside the fetal patient ${ }^{36-37}$. Because no hysterotomy is required, such surgery is not subject to the disastrous complication of preterm labor ${ }^{2}$. This is only one of many potentially wonderful application of robotics to Pediatrics ${ }^{38-45}$. However, as we will see throughout this review, the literature on robotically assisted pediatric surgery has been and continues to be rather slim ${ }^{46-50}$. Early experiences in robotic pediatric surgery have been limited ${ }^{51-54}$. However, one surgical subspeciality that has seen tremendous application of robotics since its inception is Pediatric Urology and we will see why.

It is therefore the goal of this review to summarize the current trends in pediatric robotic surgery and provide the reader with a broad but clear overview of the field, especially pertaining to the pediatric population.

But first, let us start with an update on the current surgical robots on the market and their respective characteristics.

\section{From Zeus to Da Vinci}

The first FDA-approved surgical robot in 1994 was AESOP, a voice-controlled endoscopic camera that could theoretically be used with any scope of any size. This has been integrated into Zeus, one of the two robotic systems now in clinical use for surgical procedures. AESOP and Zeus were created by Computer Motion (CMI, Goleta, Calif.) which merged in June 2003 with Intuitive Surgical (ISI, Sunnyvale, Calif.), the makers of the da Vinci system. Da Vinci was the first FDA-approved robot for use in general laparoscopic procedures (24). Since its inception in 1995, da Vinci has received generalized clearance under CE guidelines for all surgical procedures and has also received FDA clearance for general surgery, CT surgery, and urologic procedures ${ }^{55}$. Back in 2004, both Zeus and da Vinci were used for pediatric and adult surgery but nowadays, da Vinci is the only one still commercially available. To be clear on terminology when describing these systems, a surgical robot is actually a collection of wristed "servant" tools called manipulators which receive digital instructions from an interfaced computer ${ }^{56}$. Thus a better term for robot would potentially be computer-enhanced tele-manipulator. 
The da Vinci system (Fig 1) consists of three major components, which are the surgeon's console (Fig 2) housing the visual display system, surgeon's control handles and user interface panels and the patient side cart. Placement of the surgeon's console, surgical cart and the Insite vision system along with the place of the assistant surgeon varies according to the operation. The patient cart contains two to three arms that control the operative instruments and an additional arm controlling the video endoscope ${ }^{57}$. Right and left arms generally control the surgical instruments whereas the center arm holds the endoscope (high resolution 30 degree endoscope with two 3 chip cameras for better depth perception. Any additional trocars can be placed for additional instruments ${ }^{6}$. During surgery, the surgeon sits at the console, using his control handles (Fig 3), which act as high-resolution input devices from his or her finger tips. This setup allows for motion scaling and tremor reduction, which are considered major advantages of the robotic system. The long, inflexible instruments of laparoscopic surgery magnify the surgeon's tremor and limit the surgeon's natural range of motion ${ }^{58}$. Robotics attempts to eliminate this constraint.

Whereas a $12 \mathrm{~mm}$ dual channel endoscope is used for the adult patient, the pediatric patient is visualized with a $5 \mathrm{~mm}$ endoscope. The standard da Vinci instrument platform for adults consists of an array of $8.5 \mathrm{~mm}$ diameter instruments which provide 7 degrees of freedom via a cable-driven system (EndoWrist, Intuitive Surgical) (Fig 4). The wrist is controlled by opposing cables, similar to human tendons and has a very smooth, fluid motion ${ }^{24}$.

Now a set of $5 \mathrm{~mm}$ instruments (fig 5) for use in smaller patients has become available, which use a new "snakewrist" design and also provide 7 degrees of freedom.

In cases of demanding tissue dissection or when an intraoperative change of the operative field is necessary, a fourth robotic arm could be of great benefit. A new edition of the $4^{\text {th }}$ arm da Vinci system is currently available. A fourth arm additionally obviates the need for the presence of an assistant surgeon and thus enables one-man surgery.

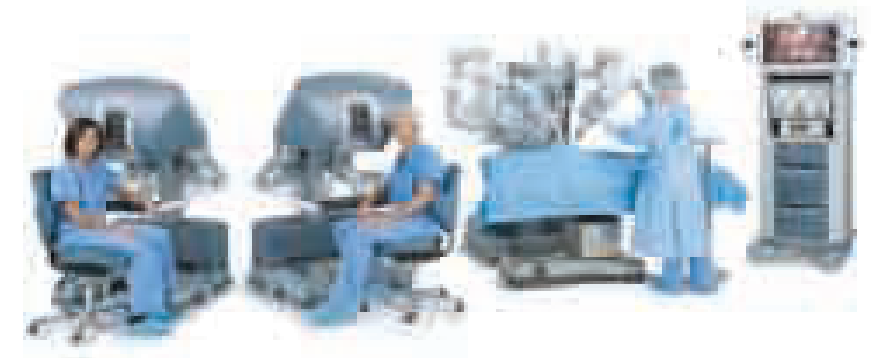

Figure 1: da Vinci ${ }_{\circledast} \mathrm{Si}^{\mathrm{TM}}$ Surgical System

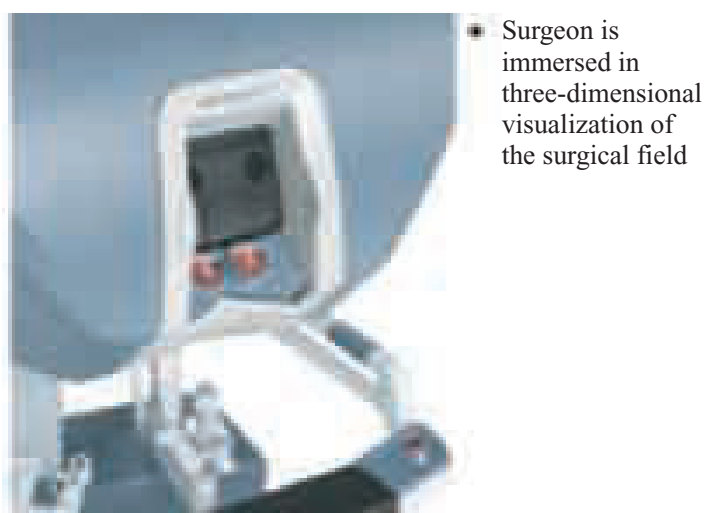

Figure 2: Da Vinci surgical console

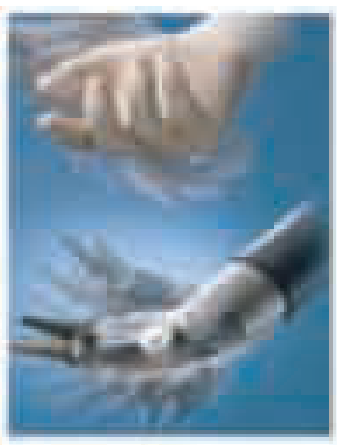

- Traditional laparoscopic instruments are straight and do not bend

- EndoWrist instruments move like a human wrist

* Allows increased dexterity, maneuverability and precision

Figure 3: Wrist \& Finger Movement

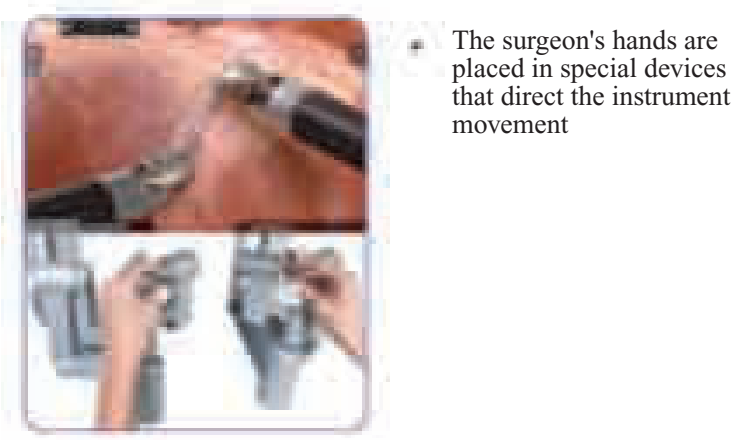

Figure 4: Surgeon Directs the Instruments

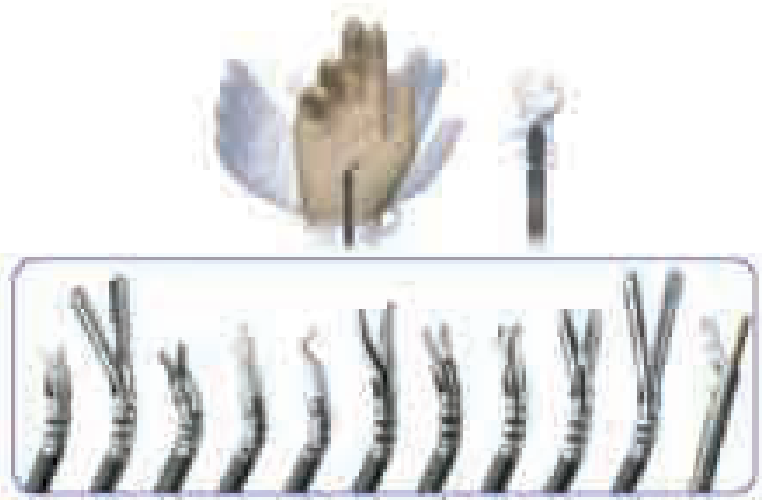

Figure 5: EndoWrist - $5 \mathrm{~mm}$ Instruments 


\section{Advantages and Disadvantages of Robotic Surgery}

Without any doubt, robotic surgery has many advantages over traditional or open surgery ${ }^{59-60}$. These advantages are very similar to conventional laparoscopy and include reduced risk of hemorrhage, which decreases the need for blood transfusions, smaller incisions, reducing postoperative pain, decreases healing time, reduces the need for postoperative analgesics and decreases scarring. Additionally, although the procedure duration is slightly longer than traditional laparoscopy, hospital stay is comparable to laparoscopic procedures and patients are able to return to their lives relatively quickly. Another important consideration over traditional or open surgery is the fact that in laparoscopy and robotic surgery, exposure of internal organs to the environment is minimal which might play a role in decreasing the chance of infection. Main features of robotic systems that confirm superiority to traditional laparoscopy and thoracoscopy are the physical separation of the surgeon from the patient, 7 degrees of freedom including grasping of the robotic arms (compared with 4 degrees plus grasping for the traditional instruments), elimination of tremors, optional motion downscaling (up to $5: 1$ ) and $3 \mathrm{~d}$ stereoscopic image ${ }^{6}$. The combination of such processing and filtering allows an unparalleled level of operative precision.

The major advantages experienced by surgeons are better degrees of freedom of the robotic instruments combined with few limitations of the endowrist movement especially in difficult anatomic sites, hand like motions of the instruments and the enhanced visualization of the operative field with a true $3 \mathrm{~d}$ view offering an impression of open access. The intuitive control of the instruments is particularly advantageous for the novice laparoscopist ${ }^{55}$.

Surgeons also see enormous improvements in intracorporeal suturing and tying knots thanks to articulated tools.

The surgeons console and the projected $3 \mathrm{~d}$ virtual operative field with personal control of the optical system presents an ergonomically comfortable position with minimal fatigue.

The master surgeon, seated at an ergonomically designed video console with an "immersive" $3 \mathrm{~d}$ display, initiates the digital instructions by controlling sophisticated hand gripsessentially joysticks with seven degrees of freedom (adding the pitch, the yaw an to the did the "pincer-like" movement to those already available). The manipulators inside the patient's body duplicate the surgeon's hand movements at the console and software filters out even physiologic hand tremors

Thus, being able to access unaccommodating places is a major theme in robot-assisted surgery ${ }^{56}$.

In small patients, the use of a magnified image via operating loupes or endoscopes is often necessary to provide more accurate visualization of their diminutive anatomy.
This enhanced visualization is taken a step further with robotics as they are capable of providing a highly magnified $3 \mathrm{~d}$ image, which adds an additional measure of safety and surgical control beyond what is available with the traditional telescope. It also improves depth perception with the ability to magnify images by a factor of 10 , allowing extremely sensitive and accurate surgical manipulation ${ }^{55}$.

Although all these advantages apply to adults as well as children, the latter group includes different factors as well. For pediatric surgeons, the feasibility and usefulness of surgical robotics is highly influenced by the nature of the procedure and probably, more importantly, by the size of the patient. Some advantages highly specific to robotics include the movement of the robot and the surgeon at the console. The robot is directly able to track the movements of the operating surgeon and translate these movements into precise actions by the robotic arms. Not different from traditional laparoscopy, in smaller patients, the surgeon demands a magnified image via endoscopes in order to properly acquire a visual of the operating field and structures of interest. In this particular aspect, robotic surgery is particularly advantageous because the robot is able to provide a superbly magnified $3 \mathrm{D}$ image which provides another measure of control on the side of the surgeon. Depth perception is greatly enhanced and this allows for very precise movements and great hand-to-eye coordination. Any surgeon might agree that visualization of the important structures might be as important if not more important than good skill and surgical technique. Being able to operate with the help of a machine allows for tremendous tremor filtration, which makes the motion of the endoscope and instrument tips steadier than with the unassisted hand. Motion scaling can be performed by the robotic console, which allows precise movements in very small anatomical areas. Another unique feature of robotics is indexing, the ability to continue moving an instrument in any direction, effectively reaching beyond the limits of the surgeon's arms or comfort zone ${ }^{24}$.

Although it appears that the robotic system features many advantages, there are also several disadvantages, some of which are relatively specific to the pediatric population. It appears that the size of the surgical robot remains an issue especially when it comes to small pediatric patients. This is of importance because rapid intraoperative access to the patient may potentially be inhibited. This might constitute a particular disadvantage for the anesthesiology team ${ }^{61-62}$. Because robotic surgery is still not the standard, especially in pediatrics, there are yet ongoing technological developments to improve the robotic surgical tools available. Although traditional laparoscopy as of now has a greater variety of surgical tools available, robotic surgery is quickly catching up. Apart from these technological disadvantages, the robotic system has been and will probably continue to be rather expensive to purchase and maintain. 
This limits the availability of robotic procedures, especially for smaller hospitals or communities. Additional training is also required in order to become proficient in robotic surgery. Because during robotic surgery, the surgeon is separated from the patient, there is a vast decrease in haptic feedback that is even greater than in traditional laparoscopy and might consitute a significant disadvantage for the operating surgeon.

Although one can agree that robotic procedures are clearly advantageous under the right circumstances, it is also obvious that these procedures tend to be more expensive due to the additional cost of acquiring and maintaining the robot and the cost of the surgical instrumentations. Thus, perhaps the most important inhibiting factor for the expansion of the system is the great cost for purchase and maintenance. ${ }^{6} \mathrm{~A}$ robot can cost 1 million dollars or more, not including the maintenance contract and expensive disposable items required for each procedure ${ }^{55-56}$.

\section{Applications of Robotic Surgery}

Surgical robotic systems are commonly classified according to the degree of direct control the surgeon has over the machine. Under this system there are three principal types of robots:

-1. Autonomous: performs a preop plan without any immediate control from the surgeon

-2. Surgical assist device: surgeon and robot share control -3. Teleoperator: the robot is completely controlled by the surgeon $^{63}$. Robotic surgery, since its inception over a decade ago has definitely seen a great increase in available procedures, techniques and availability. It is clear that under the right circumstances, robotics provides great advantages over traditional minimally invasive surgery. Although the use of robotics in adults has seen a great increase and the amount of literature is rapidly rising, pediatrics constitutes a different ballgame and the literature published on pediatric robotic procedures has been and still is rather limited. However, the prospect is that in the near future, as technological developments are increasing and procedures might be more readily available, more and more articles will be published regarding the use of robotic surgery in the pediatric population and we will be able to see the same or similar advantages that are present in the adult population. In pediatric surgery, the usefulness of the different robots is highly influenced by the size of the patient and the reconstructive nature of many pediatric surgery procedures $^{55}$. Robotic technology assists the pediatric surgeon by 1) increasing dexterity and precision of movements, 2) restoring proper hand-eye cocordination in an ergonomic position and 3) improving visualization ${ }^{63}$. Rate of complications or conversions to open surgery has been low $^{55}$.
This review will focus on the recent literature published on robotically assisted pediatric surgery. There are a few previous reviews detailing the literature up to date but no recent one, which is important because the field of robotic surgery pertaining to pediatrics has seen great innovation in the past few years.

\section{Pediatric General Surgery}

Almost a decade has passed since the first pediatric general surgery procedure was performed with the aid of a robotic system. Since then, several other procedures have been performed and more and more reports are available to determine the feasibility of general surgery procedures in the pediatric population ${ }^{64-74}$. In 2006 , Lehnert et al published a prospective study comparing operative time in conventional laparoscopic and robotically assisted Thal semifundiplication in chilren $^{75}$. In order to prove their hypothesis that operative time varies between these two procedures, the group performed a prospective study comparing operative time in 10 Thal fundoplications used with the aid of a robot and 10 traditional laparoscopic fundoplications. They found that, as expected, setup time in the robotic group was significantly longer $(20.8+-7.5 \mathrm{vs}$. $34.6+-9.2 \mathrm{~min}, \mathrm{P}<0.05)$ but the most challenging portion of the operation, which was dissection of the hiatal region was accomplished $34 \%$ faster in the robotically assisted group $(30.8+-8.7$ vs. $20.2+-5.3 \mathrm{~min}, \mathrm{P}<0.05)$. The study concluded that the robotic system is superior compared with established standard laparoscopic techniques when it comes to the procedure itself. However, the operative time benefit is counterbalanced by the increased duration of setup. Another study described the results of 15 laparoscopic fundoplications performed with the Zeus Robotic System ${ }^{58}$. The procedures consisted of one Heller myotomy with Dor fundoplication and 14 Nissen fundoplications. Patients ranged from 2 months to 18 years of age (mean $4.3 \mathrm{yrs}$ ). The authors reported no technical or equipment errors and no conversions. Further, it is interesting to note that the procedure had a learning curve in the operating surgeons since procedure time decreased from $323 \mathrm{~min}$ for the first case to $180 \mathrm{~min}$ for the last case. Setting up the robotic system for these procedures took an average of $11 \mathrm{~min}$. Heller myotomies have also been reported by other groups ${ }^{76}$. A recent article reported robotic-assisted laparoscopic Nissen fundoplication in neurologically impaired children and found that although robotic-assisted fundoplication is not yet indicated for routine fundoplication it does have benefits in children with previous gastrostomy, adhesion from previous abdominal surgery or failed primary fundoplication. Robotic fundoplication has also successfully been reported by others $^{77-78}$. In 2007, a case report was published on the robotic repair of a bochdalek congenital diaphragmatic hernia in a small neonate ${ }^{79}$. The authors concluded that the repair can be successfully performed even in small neonates. 
However, it must be noted that the available domain in the abdomen for this procedure was extremely limited. Viscera reduction in children less than $3.0 \mathrm{~kg}$ is probably easier performed using traditional laparoscopic instruments. Case reports of successful robotic repair of congenital paraesophageal hiatal hernia and diaphragmatic hernias have also been described ${ }^{80-81}$. Another procedure that has been reported to be successfully performed via robotics is laparoscopic Morgagni Hernia repair ${ }^{82-83}$. The authors reported successful completion of two cases, one in a 23 month old and another in a five year old. The surgeons noted increased dexterity provided by the robotic system ${ }^{84}$. In 2007, Klein et al reported a clinical experience with a variety of pediatric surgical procedures. These included 25 Nissen fundoplications, 18 cholecystectomies, 2 Heller myotomies, 2 splenectomies, 2 Morgagni Hernia repairs and single cases of complex pyloroplasty in the chest, bowel resection, left Bochdalek congenital diaphragmatic hernia repair, esophageal atresia and tracheoesophageal fistula repair and choledochal cyst excision. The surgeons reported easier dissection, suturing and knot tying than with traditional laparoscopy. Additionally, it is important that none of the surgeons thought the lack of haptics was crucial. A preliminary report by Meehan et al describes the advantages of the robotic approach to complex hepatobiliary anomalies in children ${ }^{85}$. The group was able to successfullly perform 2 Kasai portoenterostomies and 2 choledochal cyst resections without any complications and the surgeons found the $3 \mathrm{~d}$ imaging and improved articulations particularly advantageous for these procedures. Robotic assisted choledochal cyst excisions have also been reported by other groups successfully ${ }^{86}$. A single institutional review of the first 100 robotically performed cases has been reported by Meehan and Sangler ${ }^{87}$. They were able to report the following procedures as being performed with the aid of a robot: fundoplication, cholecystectomy, splenectomy, total proctocolectomy with pullthrough, Ladd's procedure, Neuroblastoma, adrenalectomy, small-bowel rescetion, Heller myotomy Congential diaphragmatic hernia, rectal prolapse, Kasai, duodenal atresia, ovarian terratoma, ovarian cystectectomy, Meckel's, abdominal lymphangioma, hemicolectomy, pyloroplasty, gastric duplication, retroperitoneal tumor, pancreatic tumor, post mediastinal mass, mediastinal germ cell tumor, teratoma, bronchogenic cyst, intralobar sequestration, pulmonary segmentectomy. A recent article reports the use of the robotic system in 144 different pediatric surgical procedures $^{88}$. Included are many of the above mentioned procedures as well as gastric bandings, anorectal pull through for imperforate anus, nephrectomies, appendectomies, sympathectomies, inguinal hernia repairs, ovarian cyst excision, duodeno-duodenostomy and hysterectomy. Thus, one can see that a huge variety of pediatric gen surgery cases can be performed with the aid of a robot ${ }^{89-93}$. Initial efforts have already been made towards using robotics to assist in fetal surgery ${ }^{94}$.

\section{Pediatric Cardiothoracic Surgery}

In the past, only a handful of pediatric cases using the robot in cardiothoracic surgery have been reported ${ }^{95-97}$. Several reports were experimental ${ }^{98}$. Now, several other studies and case reports have been published since then. In 2007, Robinson et al published a case report describing robotic division of an unusual variant of a right aortic arch in a symptomatic 6 year old boy ${ }^{99}$. The group performed a robotic-assisted thoracoscopic division of the vascular ring with four standard left-sided video-assisted thoracic surgical incisions in about 2 hrs. At follow-up, the child tolerated the procedure extremely well. Another case report published by Baird et al. describes the first completely endoscopic closure of an atrial septal defect (ASD) in a child using the da Vinci robot and hypothermic fibrillation $^{100}$. This procedure was particularly innovative because in the past, ASD repairs have traditionally been performed using sternotomy, thoracotomy or cardioplegic arrest and this case report describes the first case of a totally robotic/endoscopic closure of an ASD in a child without the previously mentioned approaches. Therefore, the cosmetic result in this patient is more pleasing. The group concluded that the advantages of endoscopic/robotic ASD repair combine improved precision and visualization with less pain and better cosmetic results. This approach has not been used in the past because of intercostal space limitations, smaller thoracic cavity, potentially longer ischemic times due to additional suturing time required via the robotic approach. Another study by Suematsu et al (96) investigated the total endoscopic robotic-assisted repair of PDA and vascular ring in 15 pediatric patients. The group reported very successful outcomes and only one procedure had to be converted to thoracotomy due to dense adhesions from previous surgeries. Totally robotic ASD repair in older pediatric patients has been successfully reported in the past $^{101}$. Robotic pulmonary resections in children have also been performed successfully. ${ }^{102}$ Meehan et al reported the first experiences with robotic pulmonary resections even in small children and demonstrated that these procedures can be performed successfully even in small infants. This was the first report of such an experience. During the same year, Meehan et al. also reported their experiences with robotic resection of mediastinal masses in children. ${ }^{103}$ Their experiences with five different patients demonstrated that robotic surgery is safe and effective for resecting solid mediastinal chest masses in children. The average patient age was $9.8 \mathrm{yrs}$ and the pathology of the masses revealed ganglioneuroma, ganglioneuroblastoma, teratoma, germ cell tumor, and an inflammatory mass of unclear etiology. 


\section{Pediatric Urology}

By far the greatest amount of literature published on robotically assisted pediatric surgery is in the field of urology $104,105,106,107,108,109,110$. A previous review several years ago mentioned that robotically assisted pediatric urologic cases were quickly gaining interest $\mathrm{t}^{55}$. Indeed, they have and lots of different reports and reviews have since then been published ${ }^{111}$. A case report by Meeks et al describes the first experience in robotic-assisted laparoscopic diverticulectomy in a 12 year old boy with congenital bladder diverticula ${ }^{112}$. The surgeons reported that the use of robotics and $3 \mathrm{~d}$ visualization aided in safe and complete diverticulum excision and bladder reconstruction. A recent report described the early experiences of roboticassisted reconstructive operations in pediatric urology ${ }^{113}$. This report describes 3 patients who underwent extravesical ureteral reimplantation for vesicoureteral reflux and 5 children who had pyeloplasty for pelvic ureteric junction obstruction. Because these procedures, especially when performed in the pediatric population, require absolute delicacy, the use of the robot was postulated to be of advantage. The authors commented that traditional laparoscopic reconstructive urologic procedures such as the ones performed here robotically are very challenging and acquiring the proper skill and confidence takes a long time. However, the use of the robot dramatically decreased the learning curve. Casale in a recent report reviews the robotic approach to GU anomalies in children ${ }^{114}$. He mentions that laparoscopic orchiopexy is the most widely performed laparoscopic procedure in pediatric urology. Robotic surgery can be used in difficult cases such as high intra abdominal testes but is generally not the standard. When considering nephrectomies, the author states that in most cases robotics might not be necessary but can definitely be of advantage for beginning surgeons due to the decreased learning curve and greater precision with the robot. However, it must be noted that a posterior approach to the procedure is more difficult due to the size of the robotic arms except in older children. Further, pyeloplasty can both be performed laparoscopically or robotically, both procedural choices being very reasonable. Regarding appendicovesicostomy and augmentation, one can safely say that the robotic approach greatly facilitates the procedure. Several other robotically assisted pediatric urologic procedures include pyelolithotomy, adrenalactomy, bladder neck sling, ureteropyelostomy, excision of mullerian duct remnants and sacrocolpopexy. In a different report, Casale focuses on robotic pyeloplasty in children, which is the most widely performed robotic procedure in pediatric urology $y^{115}$. Another recent review article describes the current trends in pediatric minimally invasive urologic surgery ${ }^{116}$. Experiences described include adrenalectomy, nephrectomy, partial and heminephrectomy, pyeloplasty, ureteral reimplantation and lower urinary tract reconstruction.
A fairly recent case report describes the first reported instance of the use of the surgical robot to assist in performing both an appendicovesicostomy and a colon tube antigrade continent enema in a 9 year old girl with severe spinal dysraphism ${ }^{117}$. A different case report by Gundeti et al describes the case of pediatric-robotic-assisted laparoscopic augmentation ileocystoplasty and Mitrofanoff appendicovesicostomy completely intracorporeal. ${ }^{118}$ Following this experience, Nguyen et al report on 10 patients who underwent robotic assisted laparoscopic Mitrofanoff procedure successfully ${ }^{119}$. The authors concluded that this procedure is feasible and associated with satisfactory outcomes and minimal complications while having the benefit of a minimally invasive approach. When it comes to laparoscopic pyeloplasty in the pediatric population, Franco et al posed the question whether there was a difference in outcome between hand-sewn versus robotic assisted anastomosis ${ }^{120}$. After studying 29 patients, the authors concluded that robotic assisted and laparoscopic anastomosis produced similar outcomes in patients undergoing pyeloplasty. Further, operative times did not vary significantly between the 2 procedures and there did not appear to be a quantifiable benefit between the 2 procedures. In 2008, Casale et al reported their experiences with robotic ureterocalicostomy in nine patients and found that robotic ureterocalicostomy is a viable and technically feasible treatment option for patients with recurrent ureteropelvic junction obstruction or patients with difficult intrarenal ureteropelvic junctions ${ }^{121}$. Along the general trend of many case reports, Storm et al report on two cases of robotic assisted laparoscopic posterior bladder neck dissection and placement of pediatric bladder neck sling and concluded that this approach is technically feasible. ${ }^{122}$ A recent two part review by Traxel et al describes the application of minimally invasive surgery to both upper urinary tract procedures and lower urinary tract reconstructive procedures ${ }^{123-124}$. As we can see from the tremendous variety of different urologic procedures performed with the aid of robotics, pediatric urology has greatly benefitted from surgical robots. Most likely, the reason robotics took off with great interest is that the robotic system, with its ability to perform very precise movements is exceptionally well suited for reconstructive procedures and procedures in which the anatomical site is difficult to ${ }^{125}$. Additionally, the scaling of the motion allows the surgeon an additional level of precision not found in other MIS procedures. Thus, it is safe to say that robotics and pediatric urology are a match made in heaven but allowing the operating surgeons to perform procedures with greater confidence and never before seen precision. It appears that sky is the limit in the use of robotics in pediatric urology and this field will definitely continue to grow and lead to the advancement of robotics in pediatric surgery in general ${ }^{126}$. 
Current Technological Developments and Areas of Focus Because several difficulties have been reported with conventional endoscopic instrumentation which include loss of wrist articulation, poor touch feedback or haptics, fulcrum effect of the body wall on instrumentation used, loss of $3 \mathrm{~d}$ vision and poor ergonomics, there has been and will continue to be great interest in robotic surgery and the development and advancement of not only different procedures performed but also the technology being used, ranging from computer programs enabling telesurgery to instrumentation used ${ }^{88,127-128}$. As of now, there is still a greater variety of instrumentation available for traditional laparoscopy over robotic surgery. Some of the major reasons include the increased cost of developing and maintaining a robotic system. However, many technological development companies are catching on and investing into the development and improvement of robotic surgical equipment. Many articles published on robotic surgery, and particularly the applicability of robotic surgery to pediatrics mention similar limitations, which include a limited selection of robotic instruments which has impaired the performance of various surgical tasks ${ }^{88}$. There is a need for a larger variety in type and size of robotic trocars and other instrumentation, which is particularly important for use in small patients. Other areas of attention include the bulkiness of the robotic arms and the fact that the position of the operating table cannot be changed without undocking the entire system. The loss of haptics is also seen as a big disadvantage initially but many surgeons state that the excellent visual can partially compensate for the lack of feedback.

Recent advances have led to the development of radial expanding trocars (vs standard cutting trocars used in past) which have the advantage of separating tissue fibers instead of cutting them ${ }^{129}$.

These newer access systems offer numerous theoretical advantages including less tissue trauma and a tighter fascial seal, which are very helpful for minimizing unnecessary tissue stress in small children with a thin and delicate abdominal wall.

Initially, surgeons were forced to use adult instruments, but in the mid 1990s, 2 and 3mm instruments were developed, which have since then allowed working with greater ease in confined spaces.

Around same time, neonatal insufflators were developed which deliver $\mathrm{CO}_{2}$ in small puffs and thus reduce risk of over-insufflation. Now, by keeping insufflation pressures low $(8-10 \mathrm{mmHg})$ and having a close partnership with pediatric-trained anesthesiologists, surgeons are able to perform laparoscopic surgery safely in even the smallest infants ${ }^{130-133}$

In appropriate cases, SILS is now used to limit the number of incisions required to complete laparoscopic procedures and therefore lead to decreased scarring. Industry developed a single larger trocar that has three working ports for instruments. This trocar requires a $12 \mathrm{~mm}$ incision in the skin and fascia, usually at the base of the umbilicus.
By placing the incision in this area, the surgeon enables the patient to have no visible scar. With the development of instruments that can reticulate (bend and flex), surgeons are provided with more lifelike dexterity while they operate. These instruments are often necessary in SILS because all access ports are in close proximity to each other, which makes it challenging to obtain the best approach for the operation $^{2}$.

\section{Training and Skill Requirements}

Since its inception a few decades ago, laparoscopy has become a standard surgical tool for every surgeon. Nowadays, all surgical residents are trained in basic laparoscopic procedures such as appendectomy and cholecystectomy. Since MIS is the field of the future, it is important for new surgeons to be proficient in the latest surgical techniques in order to be able to accommodate the ever growing demand for less and less invasive surgeries with more pleasing cosmesis and decreased pain and length of hospital stay. Meehan et al describe their experiences using the robot in performing pediatric fundoplication and state that as soon as the staff surgeon became confident in the procedure, the surgical team allowed fourth year residents to perform the robotic procedure in order to become acquainted with and trained in using the surgical robot in pediatric procedures. ${ }^{134}$ The group reported that the biggest advantage for the robot was the steep and short learning curve, which is different from traditional laparoscopic procedures in which several procedures have a rather long and gradual learning curve. However, it should be noted that because robotic pediatric procedures are not yet readily available and widespread, it is clear that it is not feasible for all general surgery residents to start gaining experience with these techniques. Although current residents should become familiar with using the surgical robot in performing basic procedures in adults since these are a lot more common, pediatric robotic procedures are still considered rather innovative and should be a training focus of pediatric surgery fellows instead of general surgery residents ${ }^{135}$. Not until the high cost of the surgical system and equipment comes down will robotic pediatric surgery become the gold standard and be more readily available for practicing surgeons. Despite these factors, many reports on initial experiences with robotic pediatric surgery describe the steep learning curve and how quickly the operating surgeons gain confidence with the procedure and are able to overcome the current lack of haptics by excellent visualization of the operating field ${ }^{134}$. Overall, surgeons agree that robotic surgery is faster and easier to learn than the laparoscopic equivalent ${ }^{136}$.

\section{Prospective Outlook and Conclusions}

When robotic surgery was first introduced, it was with great expectations that it would change the way surgeons operate. Robotic surgery uses the basic techniques of laparoscopic surgery. However, these techniques are used through robotic arms, which are designed to mimic more accurately the motion and dexterity of human hands. 
The operating surgeon sits at a remote console and uses a $3 \mathrm{~d}$ viewer to direct the robot through hand and finger controls. However, because of the significant cost of obtaining and maintaining such a system, widespread use of robotic surgery is limited ${ }^{2}$.

With development of NOTES, surgeons have found a way to perform surgery without any incisions in the abdominal wall. With use of multichannel endoscopes, the peritoneal cavity is accessed through either the stomach or vagina, and then, by passing instruments through the working channels, surgeons can perform basic procedures. This technique has been described for appendectomies and cholecystectomies. The difficulty in this procedure lies in finding the best method to close the hole created in either the stomach or vagina. Surgeons are now investigating hybrid techniques combining NOTES with microsurgery to perform basic procedures within the peritoneal cavity ${ }^{2}$. Who knows, perhaps in the near future all these minimally invasive techniques (SILS, NOTES, robotics) will be combined in order to perform surgery on a level never before seen. True visionaries in the area focus on the robot less as a mechanical device and more as an information system, one that should be fused with other information systems. One proposed example of such a fusion is image-guided surgery also called surgical navigation. ${ }^{137-138}$ With this technique, robot-assisted surgeons will be able to see real-time $3 \mathrm{~d}$ scanner images electronically superimposed over the operative field that is displayed on the monitor. This means that surgery is going digital ${ }^{56}$. Perhaps the real future of robotics lies in microsurgery ${ }^{139}$. Telerobotic surgery has inaugurated a new era in MIS with major potential changes concerning concept and performance of surgery itself ${ }^{6}$.

A widespread integration of MIS into the pediatric surgical practice is evident from this review. There was a recent report in which older and younger surgeons were questioned on the use of robotics in their practice. Significant differences between the young and senior surgeons reflect the evolving nature of the recommendations. In this survey from 2008 , only $17 \%$ of the surgeons have previous experience in performing robotic surgery. Nevertheless, 54\% believed that robotic surgery has a role in the future for MIS in children ${ }^{140}$.

Yet, for the time being robotically assisted surgery has rapidly taken hold in several areas of adult surgery and is beginning to emerge in pediatric surgery. As can be determined from this review, recent reports state that this technology seems safe and effective. However, there is still debate whether or not there is substantive evidence that this technology is superior to open or conventional laparoscopic surgery. One thing that is for certain, however, is that current robotic systems are not cost-effective in most applications.

The current da Vinci surgical system was designed for adults yet has been made to work for children, including infants with technical success. These adaptations require more time, effort and experience to employ.
Already the system has been modified with smaller, $5 \mathrm{~mm}$ working instruments which reduces the size of the port sites and allows surgery to be performed in smaller patients. Newer versions of the system are more flexible in positioning constraints, also facilitating use in the small patient $^{141}$.

The learning curve for lap procedures performed with robotic assistance is much faster than with conventional lap procedures. Adult practice often entails repeating a single operation whereas in pediatric practice many diverse procedures are performed by a single surgeon, which limits the ability to efficiently develop the skills of conventional laparoscopy. Thus, it is very helpful to have a technique in which the training time is short and the surgeon is quickly able to learn how to perform a procedure ${ }^{141}$.

When evaluating and predicting the future of robotic surgery, it is clear that many additional studies will be needed. Because performing a prospective randomized controlled trial for surgical procedures is exceptionally difficult, careful observational studies that use more robust indicators may be the best that can be done for some time when assessing robotic surgery in children. This is unlike traditional laparoscopy ${ }^{142}$. For right now, it is safe to say that the current da Vinci system has demonstrated proof of principle that a digital information system that translates movement in a precise and accurate manner (the instrument is not a true robot but a movement transfer of master-slave mechanical device) can be used effectively in surgical procedures to take advantage of the reduced surgical trauma of laparoscopy ${ }^{141}$.

Robotic surgery gives surgeons the ability to perform essentially tremor- less microsurgery in tiny spaces with delicate precision and may enable procedures never before possible on children, neonates and fetuses. Collaboration with radiologists, engineers and other scientists will permit refinement of image-guided technologies and allow the realization of truly remarkable concepts in MIS.

While robotic surgery is now in clinical use in several surgical specialties (heart bypass, prostate removal and various GI procedures), the greatest promise of robotics lies in pediatric surgery. Fetal surgery is one example of a field that could benefit tremendously from the ability to operate exclusively by ultrasound or MRI, not to mention the possibilities created by autonomous robotic units. There is hope and belief that robotics will someday allow surgery to be performed by the least invasive methods possible and to operate on smaller and smaller structures including many that can't be accessed at all with current technologies ${ }^{44}$. Therefore, even though robotics is still rather limited, we hope to have demonstrated in this review of the current literature that the technique is extremely promising and has the potential of eventually becoming the gold standard for many procedures. Who know, perhaps conventional laparoscopy will be replaced all together. However, it is safe to say that it will be some time before the surgical community will reach this step.

\section{DISCLOSURE}

All the authors declared no competing interest. 


\section{References}

1. Nagy AG, Poulin EC, Girotti MJ, Litwin DE, Mamazza J. History of laparoscopic surgery. Can J Surg. 1992; 35(3):271-4.

2. Blatnik JA, Ponsky TA. Advances in minimally invasive surgery in pediatrics. Curr Gastroenterol Rep. 2010;12(3):211-4. Review.

3. Semm K "Endoscopic Appendectomy". Endoscopy 1983; 15 (2): 59-64.

4. Sauerland S, Jaschinski T, Neugebauer EA. Laparoscopic versus open surgery for suspected appendicitis. Cochrane Database Syst Rev. 2010 6;(10):CD001546. Review.

5. Westebring-van der Putten EP, Goossens RHM, Jakimowicz JJ, Dankelman J. "Haptics in Minimally Invasive Surgery - A Review". Minimally Invasive Therapy. 2008; 17 (1): 3-16.

6. Braumann C, Jacobi CA, Menenakos C, Ismail M, Rueckert JC, Mueller JM. Robotic-assisted laparoscopic and thoracoscopic surgery with the da Vinci system: a 4-year experience in a single institution. Surg Laparosc Endosc Percutan Tech. 2008;18(3):260-6.

7. Vereczkel A, Bubb H, Feussner H. Laparoscopic surgery and ergonomics: it's time to think of ourselves as well. Surg Endosc 2003;17:1680- 2.

8. Ercan M, Bostanci EB, Teke Z, Karaman K, Dalgic T, Ulas M, Ozer I, Ozogul YB, Atalay F, Akoglu M. Predictive factors for conversion to open surgery in patients undergoing elective laparoscopic cholecystectomy. J Laparoendosc Adv Surg Tech A. 2010; 20(5):427-34.

9. Gans SL, Berci G. Advances in endoscopy of infants and children. J Pediatr Surg. 1971; 6(2):199 -233.

10. Esposito C, Montinaro L, Alicchio F, Savanelli A, Armenise T, Settimi A. Laparoscopic treatment of inguinal hernia in the first year of life. J Laparoendosc Adv Surg Tech A. 2010;20(5):473-6.

11. Ahmed K, Wang TT, Patel VM, et al. "The role of single-incision laparoscopic surgery in abdominal and pelvic surgery: a systematic review". Surg Endosc 2011; 25 (2): 378-96.

12. Ates O, Hakguder G, Olguner M, Akgur FM. "Singleport laparoscopic appendectomy conducted intracorporeally with the aid of a transabdominal sling suture."Journal of Pediatric Surgery 2007; 42 (6): 1071-4.

13. Bucher P, Pugin $P$ et al. "Single Port Access Laparoscopic Cholecystectomy (with video)."World J Surgery 2009; 33 (5): 1015-9.
14. Halim I, Tavakkolizadeh A. "NOTES: The next surgical revolution?" International Journal of Surgery2008; 6 (4): 273-6.

15. Baron TH. "Natural orifice transluminal endoscopic surgery". The British Journal of Surgery 2007; 94 (1): $1-2$.

16. Velhote MC, Velhote CE: A NOTES modification of the transanal pull-through. J Laparoendosc Adv Surg Tech A 2009; 19:255-257.

17. Ponsky TA, Diluciano J, Chwals W, et al.: Early experience with single-port laparoscopic surgery in children. J Laparoendosc Adv Surg Tech A 2009; 19:551-553.

18. Albassam AA, Mallick MS, Gado A, Shoukry M. Nissen fundoplication, robotic-assisted versus laparoscopic procedure: a comparative study in children. Eur J Pediatr Surg 2009; 19:316-319.

19. Hubens G, Coveliers H, Balliu L, et al. A performance study comparing manual and robotically assisted laparoscopic surgery using the da Vinci system. Surg Endosc. 2003;17:1595-1599.

20. Ballantyne GH. Robotic surgery, telerobotic surgery, telepresence, and telementoring. Review of early clinical results. Surg Endosc. 2002;16:1389-1402.

21. Ballantyne GH. The pitfalls of laparoscopic surgery: challenges for robotics and telerobotic surgery. Surg Laparosc Endosc Percutan Tech. 2002;12:1-5.

22. Cadiere GB, Himpens J, Germay O, et al. Feasibility of robotic laparoscopic surgery: 146 cases. World J Surg. 2001; 25: 1467-1477.

23. Argenziano M, Oz MC, Kohmoto T, et al. Totally endoscopic atrial septal defect repair with robotic assistance. Circulation 2003; 108(Suppl 1):191-4.

24. Kant AJ, Klein MD, Langenburg SE. Robotics in pediatric surgery: perspectives for imaging. Pediatr Radiol. 2004;34(6):454-61. Epub 2004 Feb 18. Review.

25. Ballantyne GH, Moll F. The da Vinci telerobotic surgical system: the virtual operative field and telepresence surgery. Surg Clin North Am 2003;83:1293-304, vii.

26. Cadiere GB, Himpens J, Vertruyen M, et al. Evaluation of telesurgical (robotic) NISSEN fundoplication. Surg Endosc. 2001;15:918-923.

27. Ballantyne GH, Moll F. The da Vinci telerobotic surgical system: the virtual operative field and telepresence surgery. Surg Clin North Am. 2003;83:1293-1304, vii.

28. Hashizume M, Konishi K, Tsutsumi N, et al. A new era of robotic surgery assisted by a computer-enhanced surgical system. Surgery. 2002;131:S330-S333. 
29. Kim VB, Chapman WH, Albrecht RJ, et al. Early experience with telemanipulative robot-assisted laparoscopic cholecystectomy using da Vinci. Surg Laparosc Endosc Percutan Tech. 2002;12:33-40.

30. Braumann C, Menenakos C, Rueckert JC, et al. Computer-assisted laparoscopic repair of "upsidedown" stomach with the Da Vinci system. Surg Laparosc Endosc Percutan Tech. 2005;15:285-289.

31. Braumann C, Jacobi CA, Menenakos C, et al. Computer-assisted laparoscopic colon resection with the Da Vinci system: our first experiences. Dis Colon Rectum. 2005;48:1820-1827.

32. Tanna N, Joshi AS, Glade RS, et al. Da Vinci robotassisted endocrine surgery: novel applications in otolaryngology. Otolaryngol Head Neck Surg. 2006; 135:633-635.

33. McLeod IK, Mair EA, Melder PC. Potential applications of the da Vinci minimally invasive surgical robotic system in otolaryngology. Ear Nose Throat J. 2005;84:483-487.

34. Meininger D, Byhahn C, Markus BH, et al. Total endoscopic Nissen fundoplication with the robotic device bda VinciQ in children. Hemodynamics, gas exchange, and anesthetic management]. Anaesthesist 2001;50:271- 5.

35. Gutt CN, Markus B, Kim ZG, Meininger D, Brinkmann L, Heller K. Early experiences of robotic surgery in children. Surg Endosc. 2002;16(7):1083-6. Epub 2002 Apr 9.

36. Aaronson OS, Tulipan NB, Cywes R, et al. Robotassisted endoscopic intrauterine myelomeningocele repair: a feasibility study. Pediatr Neurosurg 2002;36:85-9.

37. Hollands CM, Dixey LN. Applications of robotic surgery in pediatric patients. Surg Laparosc Endosc Percutan Tech 2002;12:71-6.

38. Hollands CM, Dixey LN. Robotic-assisted esophagoesophagostomy. J Pediatr Surg 2002;37:983-5.

39. Lorincz A, Langenburg S, Klein M. Robotics and the pediatric surgeon. Curr Opin Pediatr 2003;15:262-6.

40. Malhotra SP, Le D, Thelitz DRobotic-assisted endoscopic thoracic aortic anastomosis in juvenile lambs. Heart Surg Forum 2002; 6:38-42.

41. Knight CG, Lorincz A, Gidell KM, Lelli J, Klein MD, Langenberg SE. Computer-assisted robot-enhanced laparoscopic fundoplication in children. J Pediatr Surg 2004;39:864-6.

42. Pedraza R, Weiser A, Franco I. Laparoscopic appendicovesicostomy (Mitrofanoff procedure) in a child using the da Vinci robotic system. J Urol 2004;171:1652-3.
43. Hollands CM, Dixey LN, Torma MJ. Technical assessment of porcine enteroenterostomy performed with ZEUS robotic technology. J Pediatr Surg 2001;36:1231-3.

44. Lorincz A, Knight CG, Langenburg SE, et al. Roboticassisted minimally invasive Kasai portoenterostomy: a survival porcine study. Surg Endosc 2004;18:1136-9.

45. Olsen LH, Deding D, Yeung CK, Jorgensen TM. Computer assisted laparoscopic pneumovesical ureter reimplantation a.m. Cohen: initial experience in a pig model. APMIS Suppl 2003;(109):23-25.

46. Gutt CN, Markus B, Kim ZG, Meininger D, Brinkmann L, Heller K. Early experiences of robotic surgery in children. Surg Endosc 2002; 16:1083-6.

47. Heller K, Gutt C, Schaeff B, Beyer PA, Markus B. Use of the robot system da Vinci for laparoscopic repair of gastrooesophageal reflux in children. Eur J Pediatr Surg 2002;12:239-42.

48. Le Bret E, Papadatos S, Folliguet T, et al. Interruption of patent ductus arteriosus in children: robotically assisted versus videothoracoscopic surgery. J Thorac Cardiovasc Surg 2002;123:973-6.

49. Luebbe B, Woo R, Wolf S, Irish M. Robotically assisted minimally invasive surgery in a pediatric population: initial experience, technical considerations, and description of the da Vinci Surgical System. Pediatric Endosurgery and Innovative Techniques 2003;7:385-402.

50. Mihaljevic T, Cannon JW, del Nido PJ. Robotically assisted division of a vascular ring in children. $\mathrm{J}$ Thorac Cardiovasc Surg 2003;125:1163-4.

51. Gutt CN, Markus B, Kim ZG, et al. Early experiences of robotic surgery in children. Surg Endosc 2002; 16:1083-6.

52. Woo R, Le D, Krummel TM, et al. Robot-assisted pediatric surgery. Am J Surg 2004;188:27S-37S.

53. Le D, Woo R, Albanese C. Robotically-assisted pediatric surgery. In: Langer JC, Albanese C, eds. Pediatric Minimal Access Surgery. Boca Raton, FL: Taylor and Francis 2005;479-93.

54. Hollands CM, Dixey LN. Applications of robotic surgery in pediatric patients. Surg Laparosc Endosc Percutan Tech 2002;12:71-6.

55. Woo R, Le D, Krummel TM, Albanese C.Robotassisted pediatric surgery. Am J Surg. 2004;188(4A Suppl):27S-37S. Review

56. Robotic surgery--squeezing into tight places. Berlinger NT. N Engl J Med. 2006;354(20):2099-101.

57. Luebbe B, Woo R, Wolf S, et al. Robotically assisted minimally invasive surgery in a pediatric population: initial experience, technical considerations and description of the da Vinci Surgical System. Pediatr Endosurg Innov Tech 2003;7:385-402. 
58. Computer-assisted robot-enhanced laparoscopic fundoplication in children. Knight CG, Lorincz A, Gidell KM, Lelli J, Klein MD, Langenburg SE. J Pediatr Surg. 2004;39(6):864-6; discussion 864-6.

59. Vidovszky TJ, Smith W, Ghosh J, et al. Robotic cholecystectomy: learning curve, advantages, and limitations. J SurgRes. 2006;136:172-178.

60. Corcione F, Esposito C, Cuccurullo D, et al. Advantages and limits of robot-assisted laparoscopic surgery: preliminary experience. Surg Endosc. 2005;19:117-119.

61. Parr KG, Talamini MA. Anesthetic implications of the addition of an operative robot for endoscopic surgery: a case report. J Clin Anesth. 2002;14:228-233.

62. Mariano ER, Furukawa L, Woo RK, et al. Anesthetic concerns for robot-assisted laparoscopy in an infant. Anesth Analg 2004;99:1665-7.

63. Chandra V, Dutta S, Albanese CT. Surgical robotics and image guided therapy in pediatric surgery: emerging and converging minimal access technologies. Semin Pediatr Surg. 2006;15(4):267-75. Review

64. Anderberg M, Kockum CC, Arnbjornsson E. Robotic fundoplication in children. Pediatr Surg Int. 2007;23:123-127; Epub 2006 Oct 18.

65. Lehnert M, Richter B, Beyer PA, et al. A prospective study comparing operative time in conventional laparoscopic and robotically assisted Thal semifundoplication in children. J Pediatr Surg. 2006;41:1392-1396.

66. Meininger DD, Byhahn $\mathrm{C}$, Heller $\mathrm{K}$, et al. Totally endoscopic Nissen fundoplication with a robotic system in a child. Surg Endosc.2001;15(11):1360.

67. Heller K, Gutt C, Schaeff B, Beyer PA, Markus B. Use of the robot system Da Vinci for laparoscopic repair of gastro-oesophageal reflux in children. Eur J Pediatr Surg. 2002; 12(4):239 -242.

68. Najmaldin A. Paediatric telerobotic surgery: where do we stand. Int J Med Robot. 2007; 3(3):183-186.

69. Anderberg M, Kockum CC, Arnbjo“ rnsson E. Robotic fundoplication in children. Pediatr Surg Int. 2007;23(2):123-127.

70. Klein MD, Langenburg SE, Kabeer M, et al. Pediatric robotic surgery: lessons from a clinical experience. J Laparoendosc Adv Surg Tech A. 2007;17(2):265-271

71. Knight CG, Lorincz A, Gidell KM, et al. Computerassisted robot-enhanced laparoscopic fundoplication in children. J Pediatr Surg. 2004;39(6):864-866.

72. Najmaldin A, Antao B. Early experience of tele-robotic surgery in children. Int J Med Robot. 2007;3(3):199 -202 .
73. Heller K, Gutt C, Schaeff B, et al. Use of the robot system Da Vinci for laparoscopic repair of gastrooesophageal reflux in children. Eur J Pediatr Surg 2002;12:239-42.

74. Hollands CM, Dixey LN. Robotic-assisted esophagoesophagostomy. J Pediatr Surg 2002;37:9835.

75. Lehnert M, Richter B, Beyer PA, Heller K. A prospective study comparing operative time in conventional laparoscopic and robotically assisted Thal semifundoplication in children. J Pediatr Surg. 2006;41(8):1392-6.

76. Chaer RA, Jacobsen G, Elli F, et al. Robotic-assisted laparoscopic pediatric Heller's cardiomyotomy: initial case report. J Laparoendosc Adv Surg Tech 2004; $14: 270-3$.

77. Margaron FC, Oiticica C, Lanning DA. Roboticassisted laparoscopic Nissen fundoplication with gastrostomy preservation in neurologically impaired children. J Laparoendosc Adv Surg Tech A. 2010 ;20(5):489-92.

78. Anderberg M, Kockum CC, Arnbjörnsson E. Robotic fundoplication in children. Pediatr Surg Int. 2007 Feb;23(2):123-7. Epub 2006 Oct 18

79. Meehan JJ, Sandler A.Robotic repair of a Bochdalek congenital diaphragmatic hernia in a small Neonate: robotic advantages and limitations. J Pediatr Surg. 2007;42(10):1757-60

80. DeUgarte DA, Hirschl RB, Geiger JD.Robotic repair of congenital paraesophageal hiatal hernia. DeUgarte DA, Hirschl RB, Geiger JD. J Laparoendosc Adv Surg Tech A. 2009;19 Suppl 1:S187-9.

81. Slater BJ, Meehan JJ. Robotic repair of congenital diaphragmatic anomalies. J Laparoendosc Adv Surg Tech A. 2009;19 Suppl 1:S123-7.

82. Knight CG, Gidell KM, Lanning D, Lorincz A, Langenburg SE, Klein MD. Laparoscopic Morgagni hernia repair in children using robotic instruments. J Laparoendosc Adv Surg Tech A. 2005;15(5):482-6.

83. Anderberg M, Kockum CC, Arnbjornsson E. Morgagni hernia repair in a small child using da Vinci robotic instruments: a case report. Eur J Pediatr Surg. 2009;19(2):110-112

84. Klein MD, Langenburg SE, Kabeer M, Lorincz A, Knight CG. Pediatric robotic surgery: lessons from a clinical experience. J Laparoendosc Adv Surg Tech A. 2007;17(2):265-71.

85. Meehan JJ, Elliott S, Sandler A. The robotic approach to complex hepatobiliary anomalies in children: preliminary report. J Pediatr Surg. 2007 ;42(12):2110-4. 
86. Woo R, Le D, Albanese CT, Kim SS. Robot-assisted laparoscopic resection of a type I choledochal cyst in a child. J Laparoendosc Adv Surg Tech A. 2006;16(2):179-83.

87. Meehan JJ, Sandler A. Pediatric robotic surgery: A single-institutional review of the first 100 consecutive cases. Surg Endosc. 2008;22(1):177-82. Epub 2007 May 24.

88. Alqahtani A, Albassam A, Zamakhshary M, Shoukri M, Altokhais T, Aljazairi A, Alzahim A, Mallik M, Alshehri A. Robot-assisted pediatric surgery: how far can we go? World J Surg. 2010;34(5):975-8.

89. Alqahtani AR, Albassam A. Experience with da Vinci robot-assisted procedures in children. J Laparoendosc Adv Surg Tech 2005; 15:201-216

90. Alqahtanin AR. Robotic gastric banding in adolescents and children: a comparative study. J Laparoendosc Adv Surg Tech 2007; 17:533-534

91. AL-Qahatni AR, Almaramhi H.Minimal access surgery in neonates and infants. J Pediatr Surg 2006; 41:910-913

92. Albassam AA, Mallick MS, Gado A et al. Nissen fundoplication, robotic-assisted versus laparoscopic procedure: a comparative study in children. Eur J Pediatr Surg2009; 19:179-183

93. Luebbe BN, Woo R, Wolf SA, et al. Robotically assisted minimally invasive surgery in a pediatric population: initial experience, technical considerations and description of the da Vinci surgical system. Pediatri Endosurg Innov Tech 2004;7:385- 402.

94. Kant AJ, Klein MD, Langenburg SE. Robotics in pediatric surgery: perspectives for imaging. Pediatr Radiol. 2004;34(6):454-61. Epub 2004 Feb 18. Review.

95. Le Bret E, Papadatos S, Folliguet T, et al. Interruption of patent ductus arteriosus in children: robotically assisted versus videothoracoscopic surgery. J Thorac Cardiovasc Surg. 2002;123(5):973-976

96. Suematsu Y, Mora BN, Mihaljevic T, del Nido PJ. Totally endoscopic robotic-assisted repair of patent ductus arteriosus and vascular ring in children. Ann Thorac Surg. 2005; 80(6):2309-2313

97. Suematsu Y, del Nido PJ. Robotic pediatric cardiac surgery: present and future perspectives. Am J Surg 2004;188:98S-103S.

98. Amin Z, Woo R, Danford DA, et al. Robotically assisted perventricular closure of perimenbranous ventricular septal defects: preliminary results in Yucatan pigs. J Thorac Cardiovasc Surg 2006;131:427-32.
99. Robinson BL, Nathan M, Brown DW, Baird C, del Nido PJ. Robotic division of an unusual variant of a right aortic arch. Ann Thorac Surg. 2007;84(2):670-3.

100. Baird CW, Stamou SC, Skipper E, Watts L. Total endoscopic repair of a pediatric atrial septal defect using the da Vinci robot and hypothermic fibrillation. Interact Cardiovasc Thorac Surg. 2007;6(6):828-9. Epub 2007 Sep 12.

101. Gao C, Yang M, Wang G, Wang J. Totally robotic resection of myxoma and atrial septal defect repair. Interact Cardiovasc Thorac Surg. 2008;7(6):947-50. Epub 2008 Sep 16.

102. Meehan JJ, Phearman L, Sandler A. Robotic pulmonary resections in children: series report and introduction of a new robotic instrument. J Laparoendosc Adv Surg Tech A. 2008;18(2):293-5.

103. Meehan JJ, Sandler AD. Robotic resection of mediastinal masses in children. J Laparoendosc Adv Surg Tech A. 2008;18(1):114-9.

104. Lee RS, Retik AB, Borer JG, Peters CA. Pediatric robot assisted laparoscopic dismembered pyeloplasty: comparison with a cohort of open surgery. J Urol. 2006;175(2):683-687.

105. Passerotti CC, Nguyen HT, Eisner BH, et al. Laparoscopic reoperative pediatric pyeloplasty with robotic assistance. J Endourol. 2007;21(10):1137-1140.

106. Volfson IA, Munver R, Esposito M, et al. Robot-assisted urologic surgery: safety and feasibility in the pediatric population. J Endourol. 2007;21(11):1315-1318

107. Peters CA. Robotically assisted surgery in pediatric urology. Urol Clin North Am. 2004; 31(4):743-752.

108. Lee RS, Passerotti CC, Cendron M, et al. Early results of robot assisted laparoscopic lithotomy in adolescents. J Urol. 2007;177(6): 2306 -2310.

109. Franco I, Dyer LL, Zelkovic P. Laparoscopic pyeloplasty in the pediatric patient: hand sewn anastomosis versus robotic assisted anastomosis: is there a difference? J Urol. 2007;178(4):1483-1486

110. Yee DS, Shanberg AM, Duel BP, et al. Initial comparison of robotic-assisted laparoscopic versus open pyeloplasty in children. Urology. 2006;67(3):599-602.

111. Casale P. Robotic pediatric urology. Curr Urol Rep. 2009;10(2):115-8.

112. Meeks JJ, Hagerty JA, Lindgren BW. Pediatric robotic-assisted laparoscopic diverticulectomy. Urology. 2009;73(2):299-301; discussion 301. Epub 2008 Sep 25.

113. Chan KW, Lee KH, Tam YH, Sihoe JD. Early experience of robotic-assisted reconstructive operations in pediatric urology. J Laparoendosc Adv Surg Tech A. 2010;20(4):379-82. 
114. Casale P. Laparoscopic and robotic approach to genitourinary anomalies in children. Urol Clin North Am. 2010 ;37(2):279-86. Review.

115. Casale P.Robotic pyeloplasty in the pediatric population. Curr Urol Rep. 2009;10(1):55-9. Review.

116. Lee DJ, Kim PH, Koh CJ. Current trends in pediatric minimally invasive urologic surgery. Korean J Urol. 2010;51(2):80-7. Epub 2010 Feb 18

117. Lendvay TS, Shnorhavorian M, Grady RW. Roboticassisted laparoscopic mitrofanoff appendicovesicostomy and antegrade continent enema colon tube creation in a pediatric spina bifida patient. J Laparoendosc Adv Surg Tech A. 2008;18(2):310-2.

118. Gundeti MS, Acharya SS, Zagaja GP, Shalhav AL. Paediatric robotic-assisted laparoscopic augmentation ileocystoplasty and Mitrofanoff appendicovesicostomy (RALIMA): feasibility of and initial experience with the University of Chicago technique. BJU Int. 2011 Mar;107(6):962-9. doi: 10.1111/j.1464410X.2010.09706.x. Epub 2010 Oct 13.

119. Nguyen HT, Passerotti CC, Penna FJ, Retik AB, Peters CA. Robotic assisted laparoscopic Mitrofanoff appendicovesicostomy: preliminary experience in a pediatric population. J Urol. 2009;182(4):1528-34. Epub 2009 Aug 15.

120. Franco I, Dyer LL, Zelkovic P. Laparoscopic pyeloplasty in the pediatric patient: hand sewn anastomosis versus robotic assisted anastomosis--is there a difference? J Urol. 2007;178(4 Pt 1):1483-6. Epub 2007 Aug 16.

121. Casale P, Mucksavage P, Resnick M, Kim SS. Robotic ureterocalicostomy in the pediatric population. J Urol. 2008;180(6):2643-8. Epub 2008 Oct 31.

122. Storm DW, Fulmer BR, Sumfest JM. Robotic-assisted laparoscopic approach for posterior bladder neck dissection and placement of pediatric bladder neck sling: initial experience. Urology. 2008;72(5):114952. Epub 2008 Sep 20.

123. Traxel EJ, Minevich EA, Noh PH. A review: the application of minimally invasive surgery to pediatric urology: lower urinary tract reconstructive procedures. Urology. 2010;76(1):115-20. Epub 2010 Mar 29. Review.

124. Traxel EJ, Minevich EA, Noh PH. A review: the application of minimally invasive surgery to pediatric urology: upper urinary tract procedures. Urology. 2010;76(1):122-33. Epub 2010 Mar 29. Review.

125. Hemal AK, Nayyar R, Rao R. Robotic repair of primary symptomatic obstructive megaureter with intracorporeal or extracorporeal ureteric tapering and ureteroneocystostomy. J Endourol. 2009;23(12):2041-6.

126. Muneer A, Arya M, Shergill IS, Sharma D, Hammadeh MY, Mushtaq I. Current status of robotic surgery in pediatric urology. Pediatr Surg Int. 2008;24(9):973-7. Epub 2008 Jul 31. Review.
127. Westebring-van der Putten EP, Goossens RHM, Jakimowicz JJ, Dankelman J. "Haptics in Minimally Invasive Surgery - A Review". Minimally Invasive Therapy 2008; 17 (1): 3-16.

128. Sim HG, Yip SK, and Cheng CW. Equipment and technology in surgical robotics. World $\mathrm{J}$ Urol 2006;24:128-5.

129. Lam TY, Lee SW, So HS, Kwok SP: Radially expanding trocar: a less painful alternative for laparoscopic surgery. J Laparoendosc Adv Surg Tech A 2000; 10:269-273.

130. Kalfa N, Allal H, Raux O, et al.: Tolerance of laparoscopy and thoracoscopy in neonates. Pediatrics 2005; 116:e785-791.

131. Fujimoto T, Segawa O, Lane GJ, et al.: Laparoscopic surgery in newborn infants. Surg Endosc 1999; 13:773-777.

132. Ponsky TA, Rothenberg SS: Minimally invasive surgery in infants less than $5 \mathrm{~kg}$ : experience of 649 cases. Surg Endosc 2008; 22:2214-2219.

133. Bax NM. Laparoscopic surgery in infants and children. Eur J Pediatr Surg 2005;15:319-24.

134. Meehan JJ, Meehan TD, Sandler A. Robotic fundoplication in children: resident teaching and a single institutional review of our first 50 patients. J Pediatr Surg. 2007;42(12):2022-5

135. Velde EA, Bax NM, Tytgat SH et al. Minimally invasive pediatric surgery: increasing implementation in daily practice and resident's training. Surg Endosc 2008; 22:163-166.

136. Meehan JJ, Meehan TD, Sandler A. Robotic fundoplication in children: resident teaching and a single institutional review of our first 50 patients. J Pediatr Surg. 2007;42(12):2022-5.

137. Temple MJ, Langer JC. Image-guided surgery for the pediatric patient: ultrasound, computerized tomography and magnetic resonance imaging. Curr Opin Pediatr 2003;15:256-61.

138. Shlomovitz E, Amaral JG, Chait PG. Image-guided therapy and minimally invasive surgery in children: a merging future. Pediatr Radiol 2006;36:398-404.

139. Schwaitzberg SD. Raising the technology bar in minimally invasive surgery: look how far we've come. Surg Endosc. 2010;24(5):983.

140. Jones VS, Cohen RC. Two decades of minimally invasive pediatric surgery-taking stock. J Pediatr Surg. 2008;43(9):1653-9.

141. Peters CA. Pediatric robotic-assisted surgery: too early an assessment? Pediatrics. 2009;124(6):1680-1.

142. Salminen PT, Hiekkanen HI, Rantala AP, et al. Comparison of longterm outcome of laparoscopic and conventional Nissen fundoplication: a prospective randomized study with an 11-year follow-up. Ann Surg 2007;246:201-6. 